\title{
CONHECIMENTOS DA EQUIPE DE ENFERMAGEM SOBRE TERAPIA TRANSFUSIONAL*
}

Luiz Anildo Anacleto da Silva ${ }^{1}$, Mara Beatriz Somavilla ${ }^{2}$

\begin{abstract}
RESUMO: Esta pesquisa teve como objetivo avaliar o nível de conhecimento da equipe de enfermagem sobre os cuidados de enfermagem a serem adotados na terapia transfusional. Trata-se de uma pesquisa qualitativa com a aplicação de uma pergunta aberta a equipes de enfermagem de unidades de internação. Evidenciou-se a necessidade de maior conhecimento sobre a prática da terapia transfusional, reestruturação das propostas de educação e redefinição no processo de trabalho da equipe de enfermagem. A realização deste estudo permitiu melhor compreensão da especificidade dos cuidados de enfermagem em terapia transfusional. Foi possível compreender que o exercício profissional e a realização de cuidados qualificados estão atrelados à contínua construção de conhecimentos e, consequentemente, à utilização dos preceitos de educação permanente no trabalho.
\end{abstract}

PALAVRAS-CHAVE: Cuidados de enfermagem; Educação continuada, Transfusão de componentes sanguíneos; Enfermagem.

\section{THE KNOWLEDGE OF NURSING TEAM ON TRANSFUSION THERAPY}

\begin{abstract}
This study aimed to evaluate the knowledge level of nursing staff on nursing care to be adopted in transfusion therapy. This is a qualitative study which posed one open question the nursing staff of inpatient units. The study showed the need for more knowledge about the practice of transfusion therapy, the restructuring of education proposals and redefinition of the nursing staff work process. This study allowed a better understanding of the specificity of nursing care in transfusion therapy. It reveals that the professional practice and the delivery of skilled care are linked to the ongoing construction of knowledge and hence to the use of the precepts of continuing education at work.
\end{abstract}

KEYWORDS: Nursing care; Continuing education; Transfusion of blood components; Nursing.

\section{CONOCIMIENTOS DEL EQUIPO DE ENFERMERÍA SOBRE TERAPIA TRANSFUSIONAL}

RESUMEN: Esta investigación tuvo como objetivo evaluar el nivel de conocimiento del equipo de enfermería sobre los cuidados de enfermería a ser adoptados en la terapia transfusional. Se trata de una investigación cualitativa con la aplicación de una pregunta abierta a equipos de enfermería de unidades de internación. Quedó evidente la necesidad de mayor conocimiento sobre la práctica de la terapia transfusional, reestructuración de las propuestas de educación y redefinición en el proceso de trabajo del equipo de enfermería. La realización de este estudio permitió mejor comprensión de la especificidad de los cuidados de enfermería en terapia transfusional. Fue posible comprender que el ejercicio profesional y la realización de cuidados calificados están atraillados a la continua construcción de conocimientos y, consecuentemente, a la utilización de los preceptos de educación permanente en el trabajo.

PALABRAS CLAVE: Cuidados de enfermería; Educación continuada; Transfusión de componentes sanguíneos; Enfermería.

*Artigo extraído de Trabalho de Conclusão de Curso apresentado ao Departamento de Enfermagem da Universidade Federal de Santa Maria-UFSM.

${ }^{1}$ Enfermeiro. Doutor em Enfermagem. Professor Adjunto do Departamento de Enfermagem da UFSM.

${ }^{2}$ Enfermeira da Unidade de Clínica Médica do Hospital de Caridade de Ijuí-RS.

Autor correspondente:

Luiz Anildo Anacleto da Silva

Universidade Federal de Santa Maria

Rua Antonio Boenig, 268 - 98700-000 - Ijuí-RS, Brasil

Recebido: 14/10/09

E-mail: luiz.anildo@smail.ufsm.br

Aprovado: 22/04/10 


\section{INTRODUÇÃO}

A hemoterapia hoje se constitui em uma das alternativas terapêuticas mais efetivas no tratamento de determinadas patologias e na reposição de hemocomponentes e hemoderivados essenciais à manutenção da vida. Os hemocomponentes são parte de um todo que podemos nomear de 'sangue total', o qual é doado de forma voluntária, após realizados todos os exames necessários. No processamento, interpõemse alguns processos físicos, dos quais pode advir o concentrado de hemácias, o plasma fresco congelado, o concentrado de plaquetas e o crioprecipitado.

Compreendem-se por hemoderivados os componentes que são produzidos através da industrialização do plasma: a albumina, imunoglobulinas e fatores de coagulação (VII, VIII, IX e complexos protrombínicos). Assistencialmente, cabe à Enfermagem, juntamente com a equipe médica, o cuidado com a instalação e a administração desta terapêutica.

O objetivo deste estudo foi evidenciar os conhecimentos da equipe de enfermagem em relação aos cuidados a pacientes em terapia transfusional em unidades de internação, de um hospital de grande porte, de atenção a média e alta complexidades.

No desenvolvimento deste estudo foram observadas limitações no que diz respeito a publicações desta temática na área de Enfermagem, deste modo, apresentaremos uma breve revisão de literatura sobre os cuidados de enfermagem em terapia transfusional.

\section{REVISÃO DE LITERATURA}

Recomenda-se que as transfusões sanguíneas devam ser realizadas por profissional médico ou de enfermagem, habilitado e qualificado ${ }^{(1-2)}$. Os cuidados preconizados nas hemotransfusões incluem a utilização de equipo livre de pirógenos e com materiais descartáveis que incluam um filtro capaz de reter coágulos e agregados ${ }^{(3)}$. Os hemocomponentes devem ser infundidos em um período máximo de quatro horas, sendo que a infusão de crioprecipitado deve ser administrada o mais rápido possível, pois pode ocorrer uma perda de atividade do Fator VIII em decorrência da temperatura ambiente ${ }^{(4)}$. Estão contraindicadas a adição de medicamentos à bolsa do hemocomponente e a infusão na mesma linha venosa, com exceção da solução de cloreto de sódio a 0,9\%, em casos excepcionais e bem recomendados ${ }^{(3)}$. A conduta de infundir unidades à temperatura de $4^{\circ} \mathrm{C}$ não acarreta prejuízos ao receptor desde que observada a velocidade-limite do volume infundido inferior a $100 \mathrm{ml} / \mathrm{min}$, pelo tempo mínimo de 30 minutos $^{(5)}$.

Recomenda-se iniciar a infusão de forma lenta, em média 20 gotas por minuto, permanecendo o responsável pelo procedimento transfusional junto ao paciente, por tempo mínimo de 10 minutos, para avaliação de possíveis alterações dos dados vitais. É comum que no início da infusão as reações transfusionais mais graves podem ocorrer. A observação facilita a pronta intervenção nas reações adversas ${ }^{(3)}$. A bolsa do hemocomponente deve permanecer à altura de, aproximadamente, um metro acima do acesso venoso, o que permite um fluxo adequado. Após 15 minutos de infusão, sem alterações nos sinais vitais, a velocidade de gotejamento pode ser aumentada, observando-se a relação de tempo (em média 2 h: 50 gotas/min) e de volume a serem administrados (média $300 \mathrm{ml}$ ), consignados com o estado geral do paciente e a prescrição médica ${ }^{(5-6)}$.

O fracionamento do sangue total tem como vantagem o melhor uso quanto ao aproveitamento e eficácia, aumento do tempo de validade dos componentes sanguíneos, além de diminuição do risco de reação transfusional. Esses benefícios serão obtidos quando há a real necessidade de transfusão e prescrição adequada do hemocomponente em relação à indicação clínica $^{(6)}$.

A transfusão de concentrado de hemácias é indicada para aumentar a massa eritrocitária em pessoas que necessitam melhorar a capacidade de transporte de oxigênio e em usuários com perda sanguínea aguda. A indicação do concentrado de hemácias deve basear-se em dados clínicos e não apenas por avaliação laboratorial. A perda crônica ou produção diminuída de hemácias acarreta um prejuízo no transporte de oxigênio (hipoxemia anêmica), porém, há vários casos em que existe anemia sem manifestações clínicas; para estes casos, deve-se buscar a causa e o seu tratamento ${ }^{(4)}$. Em tais situações, antes de indicar uma transfusão, outras medidas terapêuticas devem ser analisadas, como a infusão de ferro e eritropoetina ${ }^{(5,7)}$.

O plasma é utilizado para fornecer reposição de fatores de coagulação para pessoas com doença hepática, coagulação intravascular disseminada e coagulopatia diluicional resultante de carga ou de reposição maciça de volume ${ }^{(6)}$. O plasma fresco congelado é preparado, a partir do sangue total, pela separação e congelamento do plasma dentro de seis horas após a coleta, também pode ser uma importante 
fonte de reposição de imunoglobulinas em crianças com imunodeficiências secundárias à enteropatia com perdas de proteínas, em casos severos de edema angioneurótico e para reposição em plasmaférese terapêuticas em portadores de púrpura trombocitopênica trombótica ou síndrome hemolítica-urêmica ${ }^{(4-5,7)}$.

O crioprecipitado é a parte insolúvel do plasma; permanece como um precipitante branco depois que o plasma é descongelado a $4^{\circ} \mathrm{C}$ em condições especiais. Depois do descongelamento, este plasma deverá ser centrifugado à temperatura de $4^{\circ} \mathrm{C}$ e separado do material insolúvel, a frio, em sistema fechado. Ele está indicado para o controle de sangramento associado a deficiências ou defeitos de um dos fatores de coagulação, como, por exemplo, para o tratamento de hemofilia A, doença de Von Willebrand, hipofibrinogenemia e deficiência de fator VIII ${ }^{(4,6-7)}$.

As plaquetas têm a função de atuar como tampão hemostático no endotélio vascular, e sua indicação clínica visa prevenir ou controlar hemorragias com baixa contagem de plaquetas (trombocitopenia). O concentrado de plaquetas consiste de uma suspensão de plaquetas em plasma, preparada mediante dupla centrifugação de uma unidade de sangue total, sendo importante que este componente não seja colhido em tempo maior que 15 minutos $^{(4,6-7)}$.

A administração de sangue e de hemocomponentes demanda conhecimento das técnicas de aplicação, riscos e capacidade de intervir de forma efetiva nas complicações $^{(8)}$. Institucionalmente, os cuidados básicos de enfermagem previstos incluem: verificar se o paciente ou responsável assinou um termo de consentimento autorizando o procedimento; conferir qual o hemocomponente solicitado, a determinação do tipo sanguínea e a prova cruzada em relação a transfusão; comparar as etiquetas para ter certeza de que o grupo 'ABO' e o tipo 'RH' estão de acordo com a compatibilidade do registro; e examinar o sangue quanto à presença de bolhas, coloração diferente ou turvação. Bolhas de ar podem indicar crescimento bacteriano e cor anormal ou turvação podem ser sinais de hemólise ${ }^{(8)}$. O profissional deve certificar que o hemocomponente será administrado após 30 minutos depois de retirado do refrigerador; se houver indicação de aquecimento, este deve ser feito de forma controlada, com sistema de aquecedores próprios e com termômetros para controle de temperatura ${ }^{(3,8-9)}$.

Importante também é: identificar o paciente, pedindo-lhe que diga seu próprio nome e confrontando com a identificação da pulseira/bracelete ${ }^{(3)}$; conferir duas vezes o cartão do usuário, sistema no qual consta o nome e o devido número da bolsa; e monitorizar batimentos/ausculta cardíaca, frequência respiratória, temperatura e monitoramento da pressão arterial para estabelecer um referencial para comparação posterior dos sinais vitais ${ }^{(8)}$.

Inclui-se nos cuidados a adoção de medidas de proteção aos trabalhadores e a obediência irrestrita às normas de biossegurança. Estas se justificam pelo fato de que estudos mostram um índice significativo de acidentes envolvendo artigos perfurocortantes, respingos de sangue, exposição a material químico e outros agravos. As principais causas desses acidentes estão relacionadas a materiais com defeitos, falta de proteção, descuido, pressa, falta de atenção. Embora a maioria dos trabalhadores use equipamentos de proteção individual (EPIs) como luvas e máscaras, poucos utilizam protetores faciais ${ }^{(10)}$. Contudo, a segurança no trabalho precisa transcender as normatizações, estando a efetividade destas também vinculadas a processos educativos de conscientização dos trabalhadores ${ }^{(11)}$, além da adoção de precauções padrão.

\section{METODOLOGIA}

Esta pesquisa seguiu os preceitos da Resolução n. 196/96 do Conselho Nacional de Saúde do Ministério da Saúde. O projeto foi inscrito no Conselho Nacional de Ética em Pesquisa e encaminhado e aprovado pelo Comitê de Ética em Pesquisa da Universidade Regional do Noroeste do Estado do Rio Grande do Sul (UNIJUÍ) o qual após analisado foi aprovado com o parecer $n$. 001/2007.

Trata-se de uma pesquisa de natureza qualitativa, descritiva e exploratória ${ }^{(12-13)}$. Foi realizada em um hospital macro-regional que atende média e alta complexidades, em uma área de abrangência de 125 municípios do interior do Estado do Rio Grande do Sul. Este hospital dispõe de agência própria, com comitê transfusional para o monitoramento da prática hemoterápica transfusional(3).

A pesquisa envolveu 17 trabalhadores de enfermagem, sendo 14 técnicos e três enfermeiros, das áreas de clínica médica, cirúrgica, pediátrica, obstétrica e de terapia intensiva, os quais formal e voluntariamente se disponibilizaram em participar do estudo. A escolha dos respondentes deu-se de forma aleatória ${ }^{(14)}$, e a definição do número de participantes ocorreu pelo sistema de saturação de dados ${ }^{(13)}$. Esses 
foram convidados a responder à seguinte pergunta: 'Na sua prática, que cuidados de enfermagem são implementados na terapia transfusional?' Os dados foram coletados mediante entrevista aberta, gravada em audiotape. Para a identificação dos respondentes, utilizou-se código alfanumérico, e para a interpretação dos dados utilizou-se o método de análise temática, com a construção de estruturas de resposta ${ }^{(13)}$.

\section{RESULTADOS E DISCUSSÃO}

A caracterização dos respondentes ficou assim constituída: 12 eram do sexo feminino, e cinco do sexo masculino; dois com idade entre 20 e 30 anos, 10 entre 31 e 40 anos e cinco entre 41 e 50 anos. Em relação ao tempo de atuação na enfermagem, cinco trabalhavam na empresa há menos de cinco anos, seis de 5 a 10 anos, dois de 10 a 15 anos, três de 16 a 20 anos e um respondente trabalhava na empresa há mais de 21 anos. E dois trabalhavam no turno diurno, sendo os demais no horário noturno.

$\mathrm{Na}$ análise das informações das entrevistas, emergiram uma diversidade de dados que subsidiaram a construção de três categorias, sendo aqui apresentada e discutida a categoria "necessidades de conhecimentos em relação aos cuidados de enfermagem com hemotransfusão”. A equipe evidencia a necessidade de buscar maiores conhecimentos sobre a prática da terapia transfusional, visto que os pacientes receptores da hemotransfusão, normalmente se encontram quase que exclusivamente aos cuidados da equipe de enfermagem.

Com relação à 'necessidade de conhecimento' observamos os seguintes depoimentos:

A preocupação maior é de a gente não saber o tempo necessário, o tempo que se preconiza para terminar. Outra coisa é um olhar frente à reação do paciente, pois tem pacientes que apresentam reação do sangue, então são coisas que a gente tem que observar, cuidar e chamar o pessoal do Banco de Sangue. Talvez informações melhores para a gente seriam importantes, porque é uma parte que cabe ao Banco de Sangue instalar e retirar. Então, se o pessoal da enfermagem tivesse melhores informações, orientações, que é uma coisa que a gente não tem; a gente cuida, observa, mas não sabe o que faria no momento. (E5)

Não temos muito conhecimento a respeito disso. (E9)
Outros trabalhadores referem que existe capacitação da equipe no sentido de adequar técnicas:

Existe outro caso, também, que eu analiso que o hospital já tem há um bom tempo o Banco de Sangue, e nós como unidade, quase todo mês a gente faz algum treinamento, em quimioterapia, UTI, infecção hospitalar e até hoje não foi feito nenhum treinamento sobre o Banco de Sangue, sobre o sangue, sobre as reações, tempo de infusão, para que serve o plasma, o crio [...]. Muitas vezes, o pessoal da enfermagem não sabe quais são os componentes do sangue e para que servem e muitas vezes o paciente tem uma doença e se aquele sangue que está sendo utilizado pra ele, em quê vai ajudar no quadro. Então, eu gostaria até de propor isto, o hospital precisa ter um treinamento para ter como auxiliar melhor o pessoal e, acima de tudo, quanto mais informações chegar à gente, mais completo será o atendimento e até para socorrer o paciente fica mais fácil. (E7)

Contudo, evidencia-se a falta de informação sobre cuidados específicos:

[...] até porque não tenho um entendimento mais elaborado sobre quais os cuidados mais direcionados ao sangue; pelo menos eu não tenho. A gente sempre tem aulinha sobre como instalar a sonda de nutrição, de NPT, mas sobre o sangue não temos. Eu acho que isso seria importante, porque na verdade vocês colocam o sangue ali e daí vocês saem para outros pacientes, e nós ficamos aqui, mas nós só chamamos vocês quando precisa: então é bem importante termos melhores esclarecimentos sobre isso". (E10)

Da mesma forma, outras observações:

$E u$ acho interessante haver treinamentos sobre esses hemoderivados, sobre transfusão de sangue, porque eu acho muito importante e a gente precisa estar bem ciente sobre esta matéria, deve ser explorada, ser feito palestras com os profissionais para todas as unidades para que a gente possa aprender um pouco mais sobre a hemoterapia. (E11)

Eu acho que deveria ter mais treinamento sobre isso, sobre o plasma e outros hemocomponentes que vêm da hemoterapia, que eu acho que a maioria não 
sabe. Como eu também não sei em quanto tempo tenho que infundir. Eu só sei que não pode ser muito rápido nem muito lento, mas assim quanto tempo de duração, assim, eu não sei. (E12)

A princípio, a gente não observa muito por não saber mesmo. Eu, como técnico, nunca fui orientado sobre o que fazer quando o paciente faz transfusão de sangue; nunca parei pra pensar o que poderia acontecer durante a infusão, mas por não saber do que poderia vir a acontecer, não saber praticamente nada da rotina do Banco de Sangue e como funciona uma transfusão sanguínea. (E17)

A análise das respostas permite constatar que há necessidade de reestruturação das propostas de educação no trabalho, assim como a redefinição no processo de trabalho. A educação nesta perspectiva está vinculada às transformações dos sujeitos, na medida em que cria oportunidades de desenvolvimento pessoal e profissional, com uma visão crítica e responsável acerca da realidade cotidiana. Isto conflui para a elaboração/construção de um conhecimento que se reflete na atuação pessoal, profissional e social ${ }^{(15)}$.

A educação permanente no trabalho, nesta perspectiva, busca transformar as práticas profissionais existentes através de respostas construídas a partir das reflexões sobre o ambiente de trabalho. Assim, a educação permanente pode ser entendida como 'aprendizagem-no-trabalho', pois acontece a partir do cotidiano das pessoas e das organizações, ou seja, é no processo de trabalho que essa se constrói, se viabiliza e se torna efetiva. Para tanto, as necessidades educativas partem da realidade do trabalho, sendo estas mediadas por conhecimentos e experiências dos sujeitos. A educação, portanto, consiste em implementar atividades que possam congregar preceitos teóricos com a experiência dos trabalhadores, no sentido de fortalecer suas práticas.

As concepções educativas, com vistas à construção do conhecimento, vêm sendo revisitadas, com uma convergência que busca a renovação do 'saber fazer educativo', criando novas possibilidades para inovar a realidade pessoal e profissional em enfermagem, numa prática dialógica entre o individual e o coletivo. Busca-se também criar espaços para que os profissionais se apropriem de maneira significativa, crítica e criativa do conhecimento acumulado, bem como exercitem uma práxis transformadora, colaborando com a construção da cidadania e com o envolvi- mento na transformação da realidade ${ }^{(16)}$.

As inovações científicas atreladas ao 'fazer profissional' implicam na contínua construção de conhecimentos e aperfeiçoamento das habilidades profissionais dentro de espaço temporal, em razão de que a formação técnica ou acadêmica não supre integralmente as necessidades da vida profissional. Neste interstício, insere-se a educação permanente como uma opção plenamente viável para a atualização dos conhecimentos, com vistas à qualificação das práticas de Enfermagem ${ }^{(16)}$.

Ouvindo os respondentes, entende-se a preocupação e o interesse em construir conhecimentos mais elaborados relacionados com a prática transfusional. Esses, além de concordarem com a problematização do assunto em estudo, sentem-se na responsabilidade de buscar um entendimento e, com isso, a reconstrução do conhecimento que se reflete no processo de trabalho. A compreensão desse conhecmiento é essencial para o desenvolvimento da prática de Enfermagem nos diversos cenários que se interpõem $^{(17)}$.

A educação no trabalho parte de alguns princípios, como a utilização: da educação como forma de transformar/transformando-se, na Enfermagem; a definição de propostas que incluam teoria e prática, que sejam contínuas, amplas, abriguem teorias diferenciadas, sejam claras e equitativas, além de suficientemente abrangentes para proporcionar o desenvolvimento integral e a potencialização dos sujeitos. Esses princípios partem de uma concepção educativa que permite aos sujeitos aprenderem a aprender, construir conhecimentos para promover a autonomia individual e coletiva, estar conectados com o seu meio cultural e profissional. Assim, o processo educativo se dá para, com e através dos sujeitos, e é na razão destes e na vinculação com o compromisso social que se projeta a educação permanente no trabalho.

\section{CONSIDERAÇÕES FINAIS}

Mostra a pesquisa que a Enfermagem tem papel preponderante no processo de trabalho exigido pela hemoterapia, porquanto, necessita manter-se atualizada quanto aos procedimentos visando à qualificação da assistência. Em princípio, todo e qualquer procedimento em saúde envolve algum tipo de risco, porém, com a transfusão de hemocomponentes e hemoderivados soma-se o fato de ser um processo complexo que exige conhecimentos específicos. 
Na presente pesquisa, pode-se constatar que os sujeitos dispõem de alguns conhecimentos. Entretanto, em razão de não se ter um processo educativo permanente, o aprendizado de conhecimentos específicos ocorre de forma assistemática, o que pouco contribui para o estabelecimento de um processo de trabalho que qualifique a sistematização da assistência de enfermagem. Embora a educação permanente, enquanto preceito, possa ocorrer em diferentes espaços e momentos, também precisa ser intencional, organizada e sistematizada, de forma que possa contribuir para o desenvolvimento critico e reflexivo dos trabalhadores, ou seja, que possa transcender a educação técnica.

Evidencia-se, também, no estudo, a necessidade da contínua construção de conhecimentos e, portanto, de educação permanente no trabalho atrelada ao processo de trabalho, daí a referência à falta de capacitação/ atualização para a qualificação da assistência de enfermagem.

O planejamento da assistência e a sua sistematização através do diagnóstico, prescrição e evolução de enfermagem constam como uma alternativa viável para a qualificação do cuidado. A especificidade do cuidado na hemoterapia é um elemento que qualifica a assistência na medida em que se possa observar as condições do paciente a partir das necessidades individuais. Estas fazem parte das estratégias no processo de trabalho, as quais direcionam as maneiras de proceder e qualificam a obtenção dos resultados planejados.

De qualquer modo, pode-se afirmar que é pertinente ao enfermeiro e à equipe a constante busca de seu crescimento e aperfeiçoamento, tanto científico quanto técnico e humano. Em se tratando de um profissional da área da saúde, vale lembrar que, frente às inovações científicas e ao advento de tecnologias, a graduação não dá conta de ser resolutiva, principalmente em questões mais específicas. Para tanto, há a necessidade de criar alternativas de educação em que se busque o acréscimo de conhecimentos, para que constantemente se construam novas competências, essenciais para fundamentar e qualificar as ações da Enfermagem.

\section{REFERÊNCIAS}

1. Ministério da Saúde(BR) Agência Nacional de Vigilância Sanitária - ANVISA, 2005. [acesso em 16 nov 2006]. Disponível: http://www.anvisa.gov.br
2. Conselho Federal de Enfermagem. Resolução n. 306, de 25 de abril de 2006. Normatiza a atuação do Enfermeiro em Hemoterapia. Rio de Janeiro: COFEN;2006.

3. Ministério da Saúde (BR). Resolução n. 153, de 14 de junho de 2004. Diário Oficial da União [Internet] 17 jan 2003 [acesso em 26 ago 2006]. Disponível: http://www. anvisa.gov.br

4. Verrastro T, Lorenzi TF, Neto SW. Hematologia e hemoterapia: fundamentos de morfologia, fisiologia, patologia e clínica. São Paulo:Atheneu; 2005.

5. Cintra EA, Nishide VM, Nunes WA. Assistência de enfermagem ao paciente gravemente enfermo. São Paulo:Atheneu; 2001.

6. Phillips LD. Manual de terapia intravenosa. Porto Alegre:Artmed; 2001.

7. Razouk FH, Reiche EMV. Caracterização, produção e indicação clínica dos principais hemocomponentes. Rev Bras Hematol Hemoter. 2004; 26(2):126-34.

8. Smeltzer SC, Bare BG. Tratado de enfermagem médicocirúrgica $10^{\mathrm{a}}$ ed. Rio de Janeiro: Guanabara Koogan; 2005.

9. Matassarim JB, Jacobs EM. Luckmann \& Sorensen. Enfermagem médico-cirúrgica: uma abordagem psicofisiológica. Rio de Janeiro:Guanabara Koogan; 1993.

10. Bitencourt MS. Análise do comportamento e conhecimento em biossegurança de profissionais que trabalham em área de risco biológico do HEMOSC [dissertação]. Florianópolis (SC):Universidade Federal de Santa Catarina; 2002.

11. Neves TP, Cortez EA, Moreira COF. Biossegurança como ação educativa: contribuições à saúde do trabalhador. Cogitare Enferm. 2006;11(1):50-4.

12. Richardson RJ. Pesquisa social: métodos e técnicas, $3^{\mathrm{a}}$ ed. São Paulo:Atlas;1999.

13. Minayo MCS. O desafio do conhecimento: pesquisa qualitativa em saúde. $19^{\mathrm{a}}$ ed. Rio de Janeiro: HucitecAbrasco;2002.

14. Polit DF, Hungler BP. Fundamentos da pesquisa em enfermagem. $3^{\mathrm{a}}$ ed. Porto Alegre: Artes Médicas, 1995.

15. Peres HHC, Leite MMJ, Gonçalves VLM. Educação continuada: recrutamento e seleção, treinamento e 
desenvolvimento e avaliação de desempenho profissional. In: Kurcgant P. Gerenciamento em enfermagem. Rio de Janeiro: Guanabara Koogan;2005. p. 138-139.

16. Peña YF, Castillo MA. Factores que influyen en la participación del personal de enfermería en la educación continua. Rev Latino-Am Enfermagem. [Internet] 2006;14(3) [acesso em 09 set 2006]. Disponível:http:// www.scielo.br/

17. Shimbo AY, Lacerda MR, Labronici ML. Processo de trabalho do enfermeiro em unidade de internação: desafios de uma administração contemporânea. Cogitare Enferm. 2008;13(2):184-93. 